\title{
NOTICIAS SOBRE LA CONSTRUCGIÓN DE LA "CASA BORDA" DE TAXCO
}

\author{
Elisa Vargas Lugo
}

Según consta en un expediente del Archivo de Notarías de la ciudad de México, 1 el año de 1767, don José de la Borda, quien a la sazón se ericontraba en la ciudad de Zacatecas, otorgó un poder especial a don Joseph Galiano "... vecino de la corte de México...", para que lo representara en todos los trámites referentes a la fundación de una Capellanía colativa, ${ }^{2}$ de $4,000.00$ pesos. De los textos de estos documentos se deduce que don Juan Joseph de Alva, "...Profesor de la Arte de Architectura...", fue el constructor de la casa que Borda habitó en el Real de Minas de Taxco.

En resumen, la información contenida en dichos documentos notariales, es la siguiente:

... Don Joseph de la Borda, es deudor de la cantidad de quatro mil pesos, a Don Juan Joseph de Alva, Profesor de la Arte Architectura, vecino de San Juan Teotihuacán, quien deseando satisfacer el anhelo que tiene su único, legítimo hijo, el Br. Dn. Joseph María de Alva, de ponerse en estado Eclesiástico, siendo medio para ello procurarle congrua, para que a su título pueda ordenarse; resolvio destinar dichos quatro mil pesos para fondo y principal de una Capellanía Cola" tiva ...,

1 Agradezco a la licenciada Silvia Bravo sus buenos servicios profesionales; tanto por la notificación acerca de la existencia de estos documentos, como por cumplir con la comisión de obtenex las fotocopias.

2 AGN MS. México, D. F Poder especial que otorga don Joseph de la Borda a don Joseph Galiano, para la fundación de una Capellania de cuatro mil pesos. Mariano Buenaventura Arroyo, Notaxio núm, 29, México 1766-1767, f. 224. a $248 \mathrm{x}$.

Se entiende por capelianía, en general, una fundación para establecer la obligación de celebrar anualmente cierto número de misas en cierta iglesia o capilla o altar. Las capellanías pueden ser de tres clases: mercenaria, también conocida como laica o profana; la cual se instituye sin intervención de la autoridad eclesiástica Se denomina mercenaria, porque el sacerdote que celebra sólo tiene derecho a la merced a honorarios que se asignen por la misa. La capellania colativa -cuyo nombre deriva de colación- se funda con autoridad del superior eclesiástico; se llama colativa porque sólo puede conferirla el obispo y se considera como beneficio eclesiástico. La capellanía gentilicia es la misma que la colativa, cuando el derecho de presentación coxresponde a cierta gente o familia designada por el fundadox.

Asociación Mexicana de Archivistas Eclesiásticos. Boletín informativo, México, Curia Central del Arzobispado de México, núm. 3, febrero de 1985, p. 24. 
etcétera. Esta decisión había sido tomada por el arquitecto de Alva, un año antes, es decir en $1766,{ }^{3}$ según consta en dicho expediente.

José de la Borda reconoció dicha deuda y para pagarla dispuso que fuera "... con hipoteca especial de dos casas principales que por suyas propias posee dicho Don Joseph de la Borda, situadas en la Plaza pública de dicho Real y Minas de Tasco". " Para tal efecto, Borda otorgó poder a don Joseph Galiano, en la ciudad de Zacatecas, el 13 de julio de 1767. El ilustre minero compareció ante el notario Francisco Barela ${ }^{5}$ para reconocer la deuda y declararse en "... legítimo dominio de dos casas situadas en la Plaza del Real y Minas de Tasco..." y manifestar que deseaba se gravaran con el objeto de fundar una capellanía con un "principal de quatro mil pesos y docientos de renta anual". ${ }^{6}$ Este documento -que es un traslado del original dado en Zacatecas- está firmado en testimonio de verdad, por el escribano Francisco Barela, con signo y rúbrica y se garantiza que fue sacado de su original el día en que se otorgó. 7 Además, la firma del notario aparece acreditada por el alcalde ordinario y corregidor de la ciudad de Zacatecas, don Cosme Sánchez de Lodosa. ${ }^{8}$

Un defensor del arquitecto de Alva, fue enviado a "dar vista" a las casas, y éste puso "varios reparos" sobre la propiedad y dominio de dichas casas, por caber la posibilidad de que los herederos de don Martín Berdugo - "... suegro que fue del mismo Borda"-, pudieran tener derechos sobre el solar donde están las casas. ${ }^{9}$ Pero dichos herederos, " . . quedaron absueltos..." por medio de "tres instrumentos". Es decir, que seguramente por medio de tres argumentos se aclaró que los descendientes de Martín Berdugo, no tenian ya ningún derecho sobre esos terrenos.

En auto del 5 de junio de 1767 , se solicitó probar que las casas de Borda no tuvieran otra carga; ${ }^{10}$ solicitud que dio como resultado la información de que sí estaban ya gravadas con otra hipoteca, tal como se lee en las siguientes frases: "y con calidad juntamente de que por estar grabadas dichas casas que aquí son de hipotecarse, a la cantidad de quatro mil pesos de la Capellania layca, que refiere el testimonio de Cavildo

3 Ibidem, f. $224 \mathrm{v}$ y $240 \mathrm{v}$,

4 rbidem, f $224 \mathrm{v}$

5 Ibidem, f. 225r -27r. Traslado del poder original otorgado en la ciudad de Zacatecas.

6 rbidem, $\mathrm{f} 225 \mathrm{v}$

7 Ibidem, f $226 \mathrm{~V}$.

8 Ibidem, f $226 \mathrm{v}-227 \mathbf{r}$.

9 rbidem, f $227 \mathrm{x} \cdot 228 \mathrm{r}$

10 lbidem, f. $228 \mathrm{v}$. 
que aquí queda también protocolado, los que recibió por igual modo de Depósito Irregular dicho Don Joseph de la Borda por el plazo de cinco años que ya están corriendo desde 16 de junio del citado año próximo pasado...".11 Esta declaración acerca de un gravamen anterior sobre la casa de Borda, se repite más adelante, como se verá. Sin embargo se le concedió tener “... en mero Depósito Irregular y fiel encomienda, o en aquel mejor modo que más conveniente sea y haya lugar, dichos cuatro mil pesos", para la Capellania colativa, precisamente por el tiempo y plazo de cinco años. Por supuesto se fijaron los réditos y condiciones, con advertencia de que en caso de que la muerte de Borda acaeciera antes de haberse pagado la hipoteca, sus herederos cumplirían dichas condiciones. Los réditos debían pagarse "... en especie de reales de oro común..." ${ }^{2}$ Don José de la Borda murió en la ciudad de Cuernavaca, el 30 de mayo de $1778,{ }^{13}$ por lo que, seguramente su hijo el presbítero don Manuel de la Borda, su heredero universal debió haber pagado esta hipoteca.

Así pues, en su debido momento el apoderado de José de la Borda -don Joseph Galiano-

... a nombre de su parte Dn. Joseph de la Borda, Hipoteca especial y expresamente las referidas dos casas altas principales, la una contigua a la otra, situadas en la Plaza pública de dicho Real y Minas de Taxco; las mismas que labró desde sus cimientos y lebantó en sitio que parte de él ocupaba una casa antigua que quedó por bienes de Don Martin Berdugo y Doña de Maria de Rivera y Ulloa ya difuntos, suegros que fueron del propio Don Joseph de la Borda, quien redimió dos mil pesos, de cierta Capellanía que de único grabamen reportaba, por cuia razon, y por otras vino a hacerse dueño, y señor de dicho citio de que no teniendo instrumento alguno que le sirviese de título directo -ya que como procedía se solicitó que se exhibeiran los títulos- se preventó con escrito a los tres de Abril del año pasado de setecientos y sesenta y dos ante Don Francisco García Delgado..., ${ }^{14}$

Alcalde Mayor de Taxco; informe que presentó acompañado de nueve testigos obteniendo así un testimonio autorizado por el escribano público de dicho Real, para probar que los descendientes, hijos y nietos del citado matrimonio Berdugo, ya no tenían ningún derecho sobre dicho

11 Ibidem, f. $229 \mathrm{v} .-230 \mathrm{r}$.

12 Ibidem, f. $230 \mathrm{v}$

13 Cfr. Elisa Vargas Lugo. La iglesia de Santa Prisca de Taxco, México, UNAM, $2 a$. edición 1982, p. 44.

14 MS. Poder especial que otorga don Joseph de la Borda .. ". etcétera, f $230 \mathrm{v}$. 
sitio, con lo cual quedó claro que "... lo ha poseído y lo está poseyendo el referido Borda, a cuyo pedimiento se abaluaron formal y solemnemente las casas sobre el fabricadas... por Peritos inteligentes Juramentados en forma, en veintiocho mil quinientos noventa y nueve pesos tres y medio reales, por ser su estructura a la moderna, de mamposteria y buena estofa." 1 "s

Por su parte, don Juan Joseph de Alva, al decidir la fundación de la capellanía para su hijo, contando ya con el reconocimiento de la deuda de Borda y sabedor de que éste, para pagarle emplearía el recurso de una hipoteca, otorgó Poder a don Baltazar de Vidaurra, con fecha 1 de octubre dicho año de 1767, para llevarse el asunto, puesto que él residía en la población de San Juan Teotihuacán. En este Poder se asienta que la hipoteca sería:

... sobre cierias casas de vivienda que tiene [José de la Borda] en dicho Real, las que hipotecaria en la forma regular y las que se hallan abaIuadas en veintinueve mil pesos, según le consta a el Poderdante, como el que la fábrica material de ellas importó como treinta y seis mil pesos, lo que así mismo le consta por aver TRABAJADO EN DICHA OBRA EL OTORGANTE, QUE ES MAESTRO DE ARCHITEGTURA ${ }^{16}$

Esta última frase no deja duda acerca de que el axquitecto que construyó la casa de José de la Borda en Taxco, fue el mencionado Juan Joseph de Alva, del cual desafortunadamente no conocemos nada más acerca de su vida y de su obra. Pero muy importante y muy destacado arquitecto debía ser, cuando josé de la Borda le encargó la fabricación de su casa, la cual constituye uno de los mejores ejemplares de arquitectura barroca residencial, en urbes mineras. Aparte de las informaciones que el citado expediente contiene, acerca de la hipoteca de las casas de Borda, se informa, claro está detalladamente, de las condiciones impuestas por el arquitecto de Alva, para el funcionamiento de la capellanía colativa que su hijo, don Joseph María de Alva, iba a disfrutar.

Es importante también hacer resaltar que en dichos documentos, se insiste en el hecho de que las casas de Borda ya tenían una hipoteca anterior a la que él pretendía hacer para pagar su deuda a su arquitecto. Así, en el escrito correspondiente a 1766, se asienta que la hipoteca se hacia mediante las diligencias de don Joseph Galiano, apoderado 
de José de la Borda “... conforme a los fundamentos que arriba deja asentados, y estar inteligenciados de que fuera de los cuatro mil pesos de la fundación de dicha capellanía, sólo cargan sobre la dicha finca otros cuatro mil", ${ }^{17}$ lo cual pone en evidencia la gran baja que sufrieron las finanzas del ilustre minero durante esos años.

\section{José de la Borda y su casa}

Don Manuel Toussaint, en su libro sobre la ciudad de Taxco ${ }^{18}$ dice que - sin señalar el lugar preciso- en la parte posterior de la "Casa Borda" está escrita, con piedrecitas, la fecha 1759. A mi no me ha sido posible localizar tal inscripción; seguramente porque habiendo pasado poco más de medio siglo, desde que Manuel Toussaint la vio, puede encontrarse ahora borrosa, ya sea porque ha aumentado la pátina o porque en muchas partes el enlucido ha desaparecido. Es de suponerse sin embargo, que dicha fecha corresponde a la terminación del edificio; fecha en que también se dedicó la parroquia de Santa Prisca, costeada por el famoso Fénix de los mineros ricos de la América. Puede pensarse $-\mathrm{y}$ resulta lógico- que las dos importantes edificaciones hayan sido construidas simultáneamente, pues, si, como consta, la construcción de la iglesia de 'Santa Prisca fue el fruto de la bonanza que le proporcionó a Borda la explotación de la mina de San Ignacio, ${ }^{19}$ también, seguramente, con la misma fortuna construyó su casa y la de su hijo, que estaba destinada a dar alojamiento a quienes ocuparan la posición de curas de la parroquia.

Se puede uno imaginar la piadosa -y a la vez vanidosa- felicidad que debe haber inundado el espíritu de Borda, quien en esos años se encontraba en la cumbre de su triunfo profesional y económico; en la cima del prestigio social, ganado con su trabajo y con la construcción de una maravillosa iglesia. Con tal bonanza extraordinaria -que ponía en evidencia a los ojos de la creyente sociedad de la época- el favor divino que acompañaba a Borda en sus empresas; con las caridades hechas entre la gente de Taxco; con las importantes obras edilicias con las que contribuyó al mejoramiento del Real de Minas, a partir

17 Ibidem, f, 2411. Por lo que informa el documento, la primera hipoteca que tuvo

la "Casa Borda" fue también paro fundar una capellanía, pero laica.

18 Manuel Toussaint. Tasco, México, Editorial "Cultura", 1931, p. 203.

19 Elisa Vargas Lugo, $o p$. cit, p. 20. 
de ese año preciso de 1759 , cundió su buena fama que fue en aumento y dejó de ser un hombre común y corriente para convertirse en un personaje con carisma, cuya aurcola brilla aún en nuestros días.

Este fue el José de la Borda, hombre triunfante, animado de profunda piedad, empeñado en una vida austera, devota y caritativa, dueño de una inteligencia privilegiada y de muchos miles de oro, quien entró a vivir en la casa construida por Juan Joseph de Alva. Aunque el presbítero Manuel de la Borda ocupó, como cura de la parroquia, la casa de menor tamaño anexa a la de su padre, la historia de la familia Borda hace suponer que José de la Borda debió haber vivido prácticamente solo en su amplia residencia, puesto que su esposa había muerto desde 1727 y su hija ingresó -aunque se desconoce la fecha- al convento de Jesús María de la ciudad de México. ${ }^{20}$

Bien pronto después de tan afortunado hallazgo de riquezas, y cuando Borda apenas estaría gozando de su casa y de su esplendorosa iglesia, alrededor de 1761, no pudo impedir que se iniciara para él una época de grandes bajas económicas, a pesar đe las incursiones que hizo por otras minas de la región. Según puede deducirse de las noticias con que hasta ahora se cuenta, acerca de los trabajos mineros de Borda, la crisis económica se fue acentuando a lo largo de unos diez años y cuando la situación se volvió insostenible optó por vender la gran custodia - pletórica de alhajas- depositada en la iglesia de Santa Prisca, pero que él había conservado como de su propiedad. La venta se efectuó entre 1773 y $1774^{21}$ y con el capital obtenido emprendió costosos y arduos trabajos en la mina de la Quebradilla, de Zacatecas, que nuevamente la Providencia le premió con sensacional bonanza, mediante la cual, a su muerte, acaecida en 1778 -como quedó dichopudo dejar enorme fortuna a su hijo Manuel, su único heredero.

No cabe duda pues, de que en los años de 1766 y 1767 , que corresponden a la fundación de la capellanía para el hijo del arquitecto de Alva, Borda pasaba por crítica situación económica ya que tuvo que hipotecar su casa dos veces; una de ellas para pagar la deuda que tenía con el arquitecto, deuda que posiblemente era aún parte de los honorarios devengados por éste.

Tan singular como la compleja personalidad de su amo y señor, es la complicada arquitectura de la "Casa Borda".

20 Ibidem, p. 16

21 Rafael García Granados. "La custodia de Borda", en Anales, IIE, núm. 1. 1937. p. 28-32. 
Causa siempre admiración el enorme volumen del edificio que -debido al declive sumamente pronunciado del terreno- presenta dos niveles en la fachada principal, que da a la plaza principal del pueblo -llamada ahora Plaza Borda- y cuatro en su parte posterior, la cual por su carácter pétreo y su altura monumental, tiene aspecto de inexpugnable fortaleza. El paño lateral de la casa, baja con fuerte inclinación de la mencionada Plaza Borda hacia la Plazuela de Bernal. Ln esta esquina suroeste sobresale vigoroso cuerpo saliente -que visto cesde el frente semeja una torre- volumen que comunica mayor interés arquitectónico a este excepcional conjunto.

Desafortunadamente no se dispone de algún plano que hubiera sido hecho cuando aún se conservaba la distribución original (por ejemplo, es difícil imaginarse ahora, dónde estuvo situada la capilla, porque seguramente que en esta casa existió una capilla doméstica), pero cuando menos se reproduce un esquema, basado en un plano moderno, que permite tener una idea del número de habitaciones que tuvo el edificio y de la cornelación estructural de las dos viviendas que lo componen, 22

La fachada principal tiene abiertas cinco puertas y una ventana pequeña en el primer registro y cuatro balcones en el segundo, con enmarcamientos - salvo la ventana pequeña- adintelados, tallados en cantera, cuyo color rosado destaca sobre el blanco encalado de los muros. A excepción de una de las puertas, todas tienen jambas de las que se elevan hasia la altura de la cornisa, a la manera en que se usaron en la capital del virreinato desde el siglo xvir, por lo que en este espacio, puede hablarse de clara influencia de la arquitectura capitalina. La entrada a cada una de las casas está colocada a eje con su respectivo balcón, en el segundo registro, pero los demás vanos se abrieron sin preocuparse por la simetría.

La portada de la Casa principal o sea la que habitó José de la Borda, se abre en el centro del ancho total del paramento que ocupan las fachadas de las dos casas y la entrada de la Casa cural-que debió haber sido habitada por primera vez por el hijo de José de la Borda- está colocada en el extremo oriente. Las otras tres puertas que se abren hacia la plaza, corresponden a locales que pueden haberse usado como tiendas o para oficinas donde se llevaran los asuntos de la minería. La balconería luce barandales corridos de hierro forjado y los balcones $\mathrm{s} / \mathrm{f}$.

22 Plano que obra en poder de la Dirección de Monumentos Históricos del INAH, 
principales se señalan discretamente por medio de separaciones transversales del mismo material y diseño. Los mayores elementos ornamentales de esta casa, son los anagramas de Jesús, María y José. Hacia la calle lateral abren dos o tres puertas más y algún balcón enrejado.

El impresionante y gigantesco paramento norte, descarga en altísimos y gruesos arbotantes, y en su enorme paño se abren sin ninguna simetría -lo cual acusa la intrincada distribución interior- diecisiete vanos: tres puertas a nivel de la calle, cinco balcones a diferentes alturas; dos de ellos enmarcados con jambas elevadas como los de la fachada principal. Estos balcones, que se encuentran en los dos extremos del muro en el nivel más alto de la construcción, parecen - por su estructuraseñalar las recámaras principales de cada una de las casas, desde donde podía disfrutarse de la vista de un paisaje sensacional, hoy en día, desgraciadamente degradado por el mal gusto de algunos edificios.

Muy difícil resulta informar con claridad la peculiar distribución interior de estas casas, que por ahora sólo pueden visitarse parcialmente, ya que, expropiadas por el gobierno del Estado de Guerrero, han sido destinadas para oficinas públicas.

Compuesta efectivamente la "Casa Borda" - como dejó dicho Manuel Toussaint- por dos viviendas estrechamente unidas, una mayor que la otra "... alrededor de un patio que ha sido dividido en su centro", 23 al penetrar en su interior, las primeras sensaciones que invaden el ánimo, son las de encontrarse y la de respirar la atmósfera de un laberinto, pues no existe, ni mucho menos, una distribución convencional, para poder guiarse y reconocer las distintas consabidas partes, de la arquitectura doméstica novohispana.

Al fondo del zaguán de la Casa principal, se abren dos arcos de cantera, ligeramente moldurados. Por el arco derecho sube la escalera al nivel superior y por el arco izquierdo, baja hacia el patio - que se localiza debajo del nivel de la plaza-y a la vez conduce a otros servicios y habitaciones de los niveles inferiores para, finalmente, encontrar salida por la fachada posterior del edificio. En cambio en la casa cural, las escaleras, se encuentran muy próximas a la entrada y son menos anchas y menos importantes.

Resulta muy interesante la solución de los patios hundidos que -aunque sólo deben recibir el calor del fuerte sol de medio díapermiten la entrada de la luz - que es sumamente brillante en Taxco

23 Manuel Toussaint, op cit., p. 203. 
durante casi todo el año- al tercer nivel, contando esta vez los registros de arriba hacia abajo. Uno de los patios luce una fuente adosada, de planta mixtilínea, que sigue un modelo muy gustado y empleado en la arquitectura civil novohispana. Desafortunadamente, las diversas modificaciones sufridas por estas casas tal vez desde el siglo pasado no permiten darse cuenta exacta -según se dijo- de cómo funcionaban las galerías que rodean a los patios en sus tres niveles, ni de cómo estuvo diseñada la comunicación y la circulación entre las diferentes habitaciones que rodean dichos patios. En el registro más alto que equivale al nivel superior, vista la casa desde la Plaza Borda, existe una curiosa pared con la que remata la división de los patios. De diseño típicamente barroco, este muro terminaba en un piñón y -aunque al parecer la más reciente restauración alteró las formas originales- se ve calado por cuatro vanos - dos arcos y dos medios arcos- de medio punto. Al centro está reforzado por un contrafuerte de cantera, rematado por un volumen mixtilíneo, que rebasa la altura de la azotea. Aparentemente a través de alguno de estos vanos, se hacía la comunicación entre las dos casas, pero no es fácil precisar -al menos para mí, tal como las obras de restauración han dejado las cosas- cual fue el espacio concreto que tuvo tal función, o si fueron varios; pero fue sin duda en esta área del edificio donde se abría ese paso privado que sólo debe haber tenido uso familiar y tal vez para el servicio doméstico. De esta manera José de la Borda podría ver fácilmente a su hijo durante el tiempo en que ambos ocuparon la "Casa Borda" y a la vez, vivir separadamente.

Las escaleras que suben y bajan recorriendo toda la altura del monumento; el escueto patio hundido; las iluminadas áreas que contrastan con otras que están siempre en penumbra; los pasillos que van en varias direcciones; los numerosos vanos que se abren hacia el interior; los amplios y los pequeños recintos; la variedad de apoyos: pilares de cantera y de mampostería que alternan con columnas de cantera; elementos todos ellos reunidos en sabia y compacta recicdumbre arquitectónica -como fiel expresión del espíritu minero- producen el intrincado y singular interior de este edificio, para el cual su barroco arquitecto hizo derroche de genio, para dar lugar a la mejor movilidad de los espacios; tarea nada fácil si se toma en cuenta la pronunciada pendiente del barranco, más que terreno propiamente dicho, sobre el cual se apoyaron los cuatro niveles.

“... un palacio de la Edad Media, español o italiano..." le pareció 
esta gran casa a Manuel Toussaint, quien tuvo la suerte de conocerlo casi intacto

... grandes contrafuertes apoyan los muros -dice Toussaint al hablar de la parte posterior- los vanos se reparten de modo caprichoso, siguiendo las necesidades del interior y la gran belleza del conjunto, mayor seguramente que la de la otra fachada, radica en el colorido que han dado los siglos a estas viejas piedras, en la sencillez grandiosa del total y en la sinceridad constructiva que no ha obedecido las leyes de una ficticia simetría. A mi modo de ver es frente a esta fachada donde puede encontrarse un recuerdo de la potencia que llegó a alcanzar y de la magnanimidad de espiritu que siempre tuvo ese prócer, que se llamó don José de la Borda. ${ }^{24}$

No cabe duda que el arquitecto Juan Joseph de Alva supo interpretar las necesidades, el gusto y el espíritu del minero de la Borda, pues como dice Toussaint, efectivamente, la casa recuerda la personalidad de su dueño en la fortaleza de su arquitectura, en la severidad de sus formas y en su grandeza volumétrica. Fue sin duda, la casa perfecta para un minero piadoso y riquísimo como José de la Borda, quien seguramente habría de guardar muchos de sus caudales en esa casafortaleza.

Otro detalle singular admira a quien contempla el paramento posterior de esta mole y es una figura de hombre -que se encuentra por encima del dintel del balcón que está próximo al contrafuerte derechodibujada con piedrecitas, al igual que la fecha localizada por Manuel Toussaint, quien por cierto, también vio esta figura puesto que aparece reproducida en una acuarela firmada por Justino Fernández, que ilustra su mencionado estudio sobre Taxco.

El personaje representado aparece de rodillas ante una cruz y la leyenda dice que la imagen conmemora la trágica caída de uno de los albañiles que trabajaron en la construcción de la casa. No deja de ser significativa esta expresión de piedad artesanal, muy de la época tanto como de la religiosidad que caractexizó a José de la Borda.

Esta sola residencia, representativa por excelencia de la arquitectura civil de las ciudades mineras, edificadas por lo general sobre superficies muy irregulares, basta para consagrar el nombre de don Juan Joseph de Alva como uno de los mejores arquitectos del siglo xvir en la Nueva España. Seguramente que su prestigio profesional era

24 Ibidem, p. 205 
grande cuando Borda le encargó la construcción de su casa. Se puede suponer que, de la misma manera que este minero buscó y llevó a Taxco algunos de los más afamados artistas del momento para que edificaran la iglesia de Santa Prisca -entre ellos el maestro Isidoro Vicente de Balbás y al pintor Miguel Cabrera cumbres del arte novorispano- quiso que un arquitecto experimentado le asegurara el buen resultado de una empresa arquitectónica tan difícil, pues evidentemente las dificultades que ofrecía el terreno sólo pudieron haber sido resueltas por un verdadero técnico en arquitectura -que supiera, ademá, trabajar con todos los adelantos técnicos que implicaba la "... estructura moderna...", como dicen los documentos- lo cual quedó plenamente demostrado con la tremenda y recia estructura, lograda por Juan Joseph de Alva. Simplemente el elevado costo de la construcción -más de treinta mil pesos de oro de la época-, para un edificio que no es lujoso, que no hace gala de tallas ornamentales ni se adorna con azulejería polícroma, pone en evidencia el sólido, dificil y por ende costoso trabajo de estructuración de la fábrica, que constituye la parte verdaderamente admirable de esta obra.

No seria imposible que este arquitecto hubiera sido también el autor de la llamada "Casa Humboldt", situada en la calle que corre justamente a espaldas de la "Casa Borda". Con gran lujo ornamental en su fachada de cantera labrada, la arquitectura interior de este otro palacete minero tiene soluciones que denotan también la inventiva y la tecnología - valga la palabra- de un arquitecto de primera categoría, como el de la "Casa Borda", si bien la "Casa Humboldt" tiene carácter más mundano y pretencioso en su conjunto. 
DOI: http://dx.doi.org/10.22201/iie.18703062e.1986.55.1279 




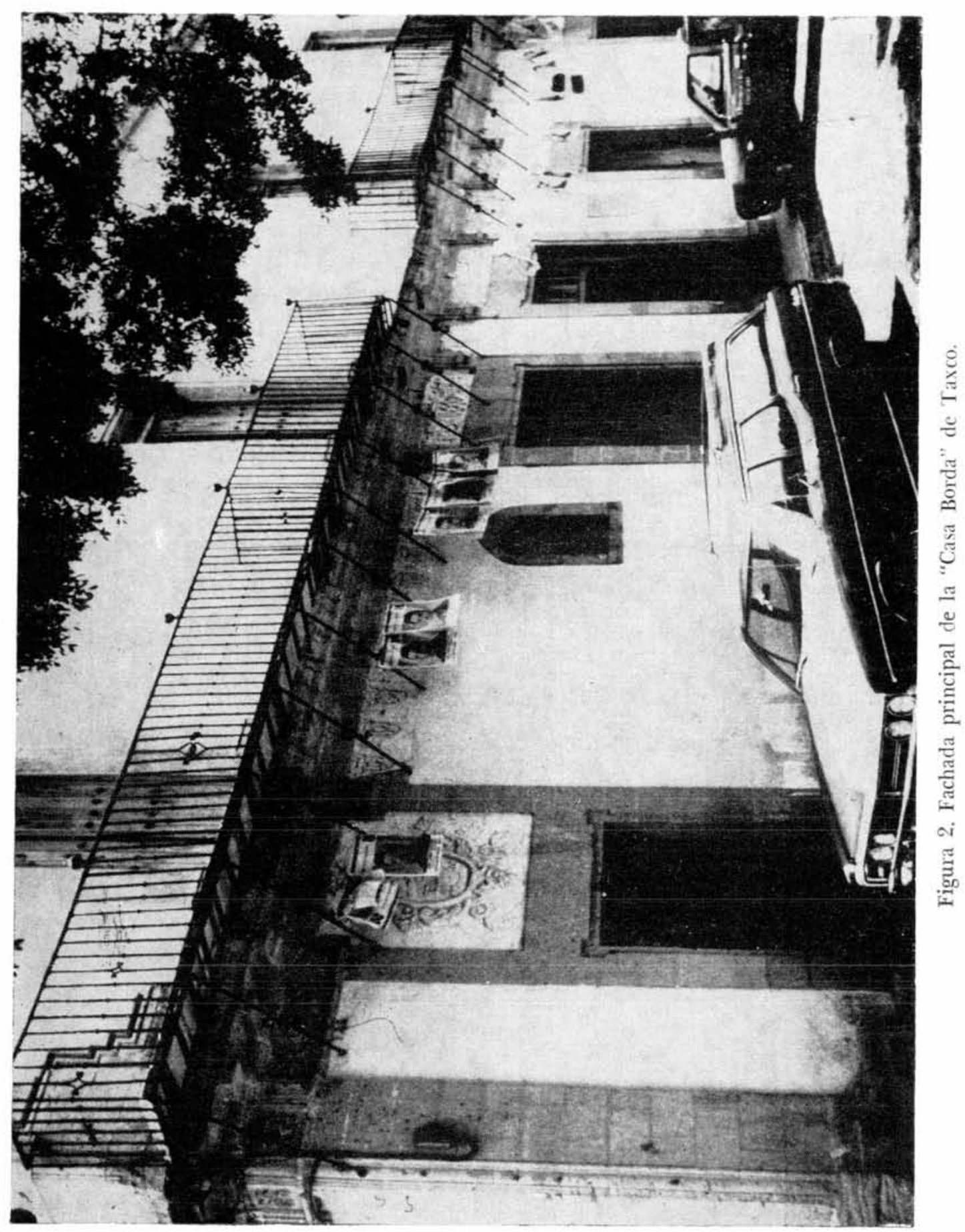


DOI: http://dx.doi.org/10.22201/iie.18703062e.1986.55.1279

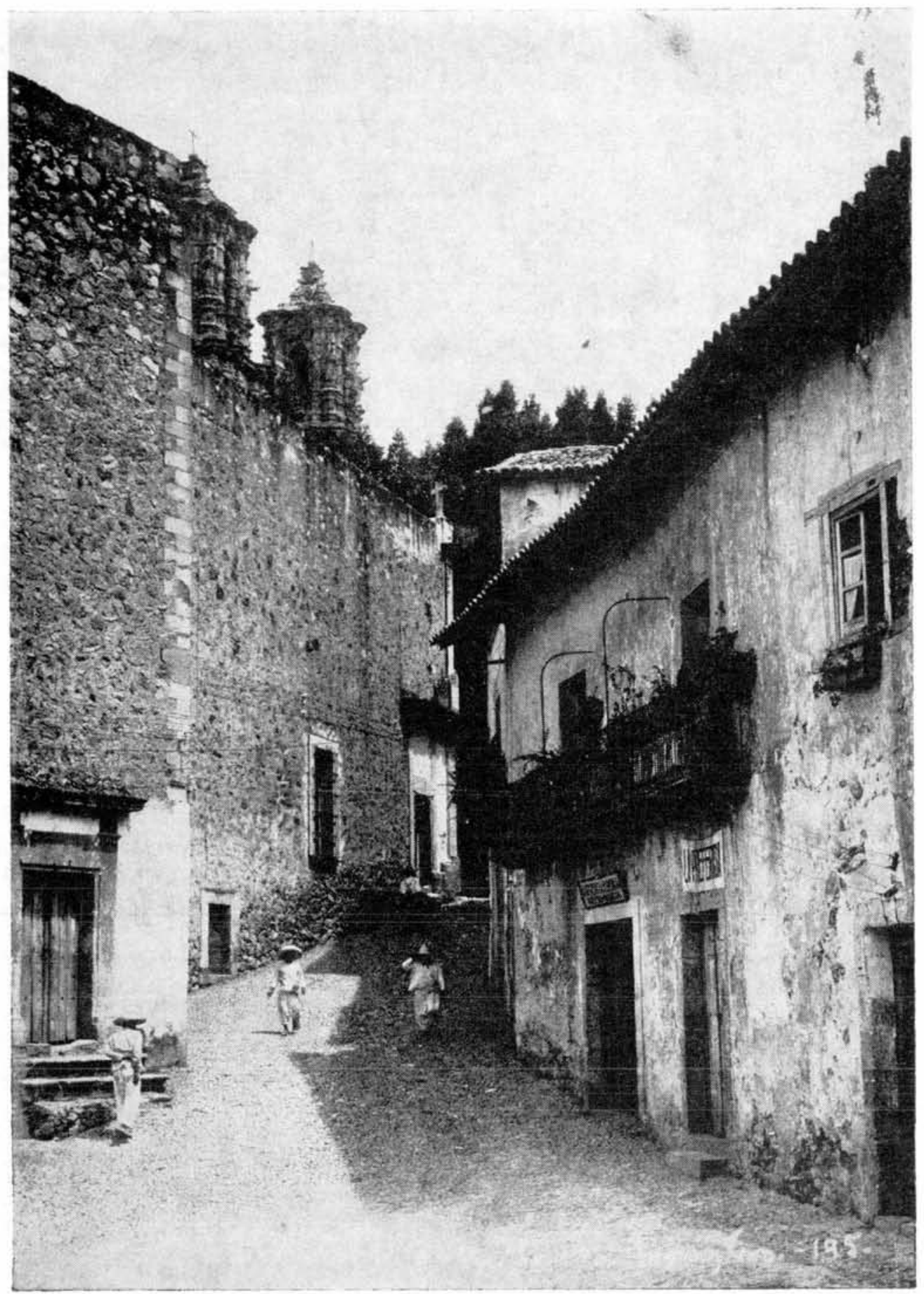

Figura 3. Fachada lateral de la "Casa Borda" de Taxco. 


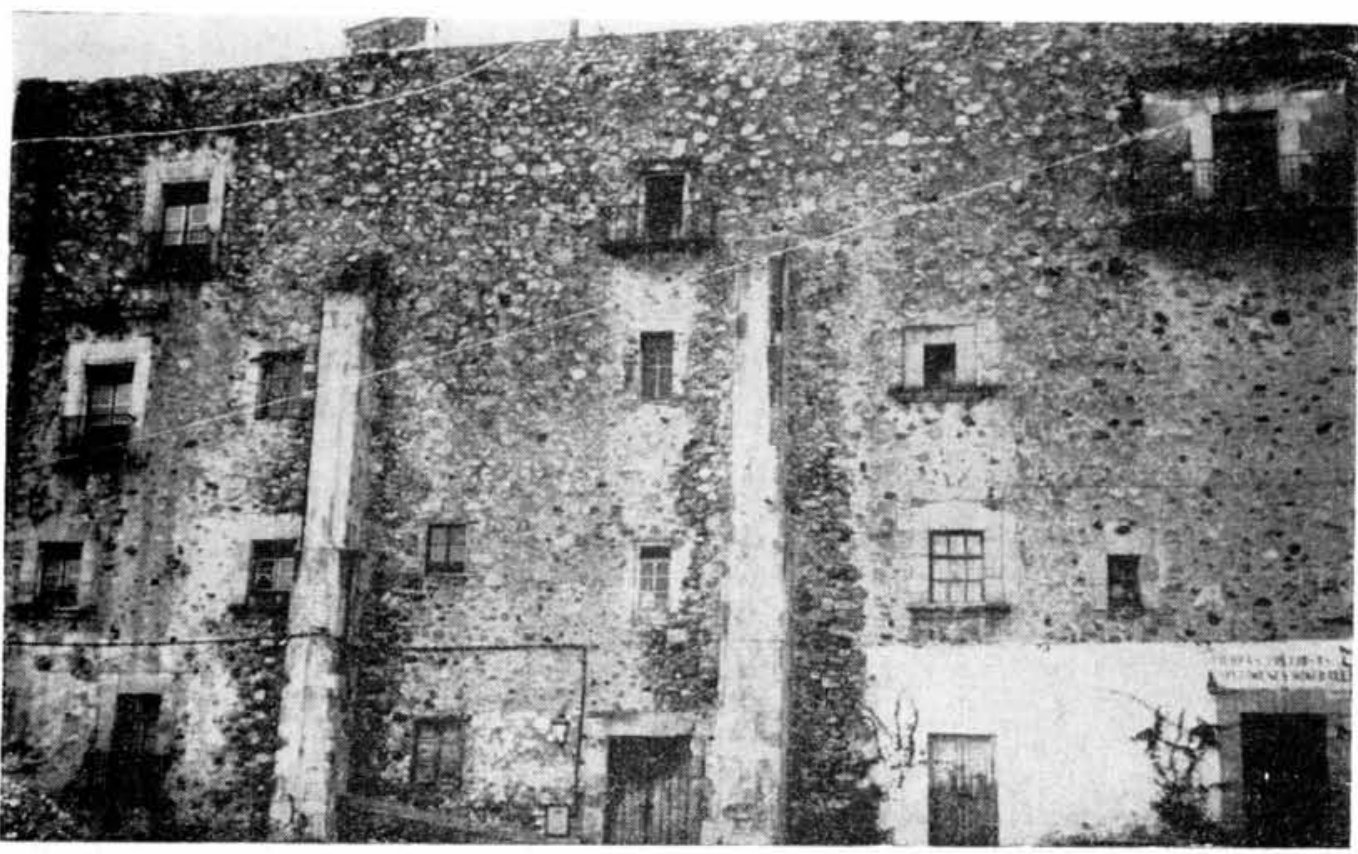

Figura 4. Fachada posterior de la "Casa Borda" de Taxco.

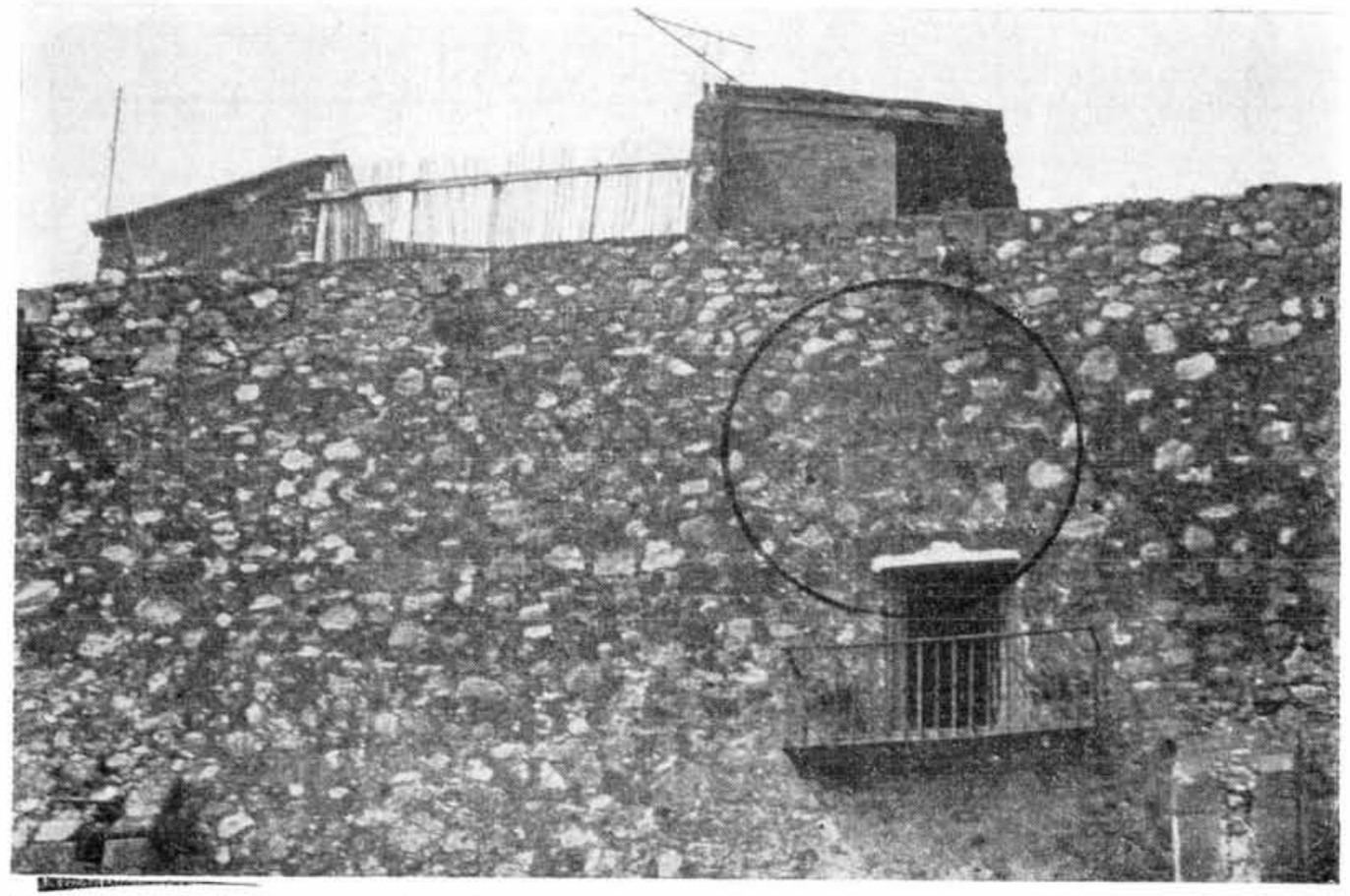

Figura 5. Fachada posterior de la "Casa Borda" de Taxco. Pormenor que muestra el área en donde se encuentra dibujada - con piedrecitas- la figura orante, hoy apenas visible. 